\title{
La violencia como medio único de sobrevivencia en México: el caso de Iguala, Guerrero
}

\begin{abstract}
La única forma de resistir a la tortura es seguir con vida. La vida, vis, es un acto de violencia, una manifestación de la cólera. Estar vivos es más violento que incendiar un autobús, es mucho más amenazador, por eso nos matan en lugar de prenderle fuego a nuestras puertas. No hay nada más violento que la fuerza de la vida y ellos lo saben. Lo único que desarma al torturador es la sobrevivencia. Incendiarlo todo es una manifestación de la ira pero no es una resistencia, no crea las condiciones para frenar la tortura, para fundar nuevas vias, es una expresión que se consume a sí misma. En este caso, la voz es mucho más violenta que el fuego. Yo estoy viva, violentamente viva y sé que mi vida, nuestras vidas, nuestras voces juntas, son más fuertes que cualquier incendio.
\end{abstract}

Tania Tagle

\section{Historia de los movimientos insurgentes de estudiantes y profesores normalistas en Guerrero}

El Estado de Guerrero hace honor a su significado, ya que es uno de los ejemplos más emblemáticos y significativos de la violencia en México, 
tanto por los antecedentes históricos y luchas legítimas como las que han infundido miedo entre su población.

Los movimientos insurgentes de jóvenes, profesores y grupos guerrilleros de orientación marxista-leninista o de cualquier otra ideología tienen orígenes tan antiguos casi como la fundación de la nación mexicana. La violencia de Estado, la represión política, militar, la tortura y las desapariciones también son fenómenos añejos que acompañan como contraparte los movimientos armados y guerrillas en esa región.

Solo en el caso de los desaparecidos, Guerrero concentra la mayor cantidad y ocupa el indecoroso primer lugar en este rubro. En esa entidad, desaparecieron 247 personas desde el año 2007 (de 989 en todo el país), de las cuales 177 fueron vistas por última vez en Iguala, lo que representa el 71,6 \% (Letra Roja, 2016). Estos números fueron informados por el Secretariado Ejecutivo del Sistema Nacional de Seguridad Pública y del Registro Nacional de Datos de Personas Extraviadas o Desaparecidas.

Cabe recordar el poblado de Iguala, precisamente en el mismo Estado, en donde, en el año 2014, desaparecieron en el mes de septiembre más de cuatro decenas de jóvenes normalistas, en un contubernio entre el alcalde de dicha comunidad, la alcaldesa, la Policía municipal y grupos ultraviolentos del crimen organizado.

En el año 1821, en el mismo sitio, fue celebrado el famoso Plan de Iguala por parte de Agustín de Iturbide y Vicente Guerrero, casi únicos continuadores del movimiento independentista de 1810. Con el Plan de Iguala culminó el hasta entonces fallido movimiento insurrecto iniciado por el cura Miguel Hidalgo en la ciudad de Dolores, Guanajuato, 11 años antes. El propio Hidalgo y la mayoría de sus seguidores, como Morelos, Matamoros, etc., habían sido pasados por las armas y decapitados como muestra del poder de la Corona Española y de la pésima estrategia política y militar de los insurgentes.

Mediante dicho plan, se concretaban los intereses perseguidos por todos los interesados en el movimiento de independencia mexicana: criollos, mestizos, indígenas e incluso el Imperio español, ya en decadencia. Era la formalización de la ansiada independencia de México. Un logro obtenido no mediante las armas, para contradecir la historia oficialista, ni la violencia armada, sino bajo una fina y concertada 
estrategia político-administrativa. Cosa que hoy más que nunca cabría revalorar y recuperar.

Quizá no sea una mera coincidencia que en el mismo sitio, en septiembre de 2014, desapareciera un autobús con más de cuarenta estudiantes de la escuela Normal de Ayotzinapa. Versiones oficiales, dos meses después, revelaron que fueron apresados por miembros de la Policía de dos municipios, mientras marchaban a una manifestación en contra del destape político de la alcaldesa de la misma entidad; los policías los entregaron a un grupo ultraviolento del crimen organizado, fueron torturados, asesinados y, presuntamente, sus cuerpos fueron calcinados y echados a un río.

O, por lo menos, esa fue la llamada "verdad histórica" que prácticamente impuso la Procuraduría General de la República (PGR), aunque en la Universidad de Innsbruck, en Austria, identificaron con restos humanos a uno de los normalistas desaparecidos; sin embargo, hasta ahora ningún otro ha sido identificado. En contraparte, el Equipo Argentino de Antropología Forense informó que, por lo menos, los restos óseos de las 19 personas incineradas (cantidad registrada hasta el momento) en el basurero de Cocula no corresponden a los normalistas desaparecidos (El Financiero, 2016).

\section{La Escuela Normal de Ayotzinapa y algunos de sus egresados: Genaro Vázquez y Lucio Cabañas}

Desde décadas atrás, Guerrero ha sido un Estado donde se reprime con mano que se pasa de dura: con matanzas de grupos enteros, desapariciones y fosas comunes a cada paso de sus zonas rurales. Como preámbulo, se tiene el asesinato en masa de cuarenta cultivadores de coco en la entrada de la ciudad de Chilpancingo, en septiembre de 1967, mientras marchaban solicitando al gobernador del Estado un aumento en el precio de la carne de coco. Se dice que solo pedían un peso más por kilo de su producto para beneficiar a sus familias. Un solo peso que, desde luego, afectaba los intereses de los caciques y empresarios del ramo. Fueron recibidos a fuego de ametralladora en la entrada de la capital. Un año antes de la matanza estudiantil del 2 de octubre en 
Tlatelolco, en la Ciudad de México, cuando el presidente Díaz Ordaz estaba al mando; de quien se dice que también estuvo implicado en el caso de los coqueros.

En los años sesenta, más de la mitad de la población de dicho Estado se encontraba en el analfabetismo, sobre todo las comunidades que se radican en la Sierra de Guerrero, unas de las regiones más castigadas por la pobreza y la falta de desarrollo. De acuerdo con el Consejo de Evaluación de la Política de Desarrollo Social, casi un cuarto de la población padecía pobreza extrema en 2014. En ese contexto, con la finalidad de abatir el atraso cultural y educativo, se creó la Escuela Normal de Ayotzinapa, cuya finalidad era entrenar profesores que se incorporaran a las escuelas rurales de las montañas:

La cultura de la letra ha sido un desafío en una zona que dirime discrepancias a balazos. En los años sesenta del siglo XX, dos terceras partes de los pobladores de Guerrero eran analfabetas. La Normal de Ayotzinapa surgió para mitigar ese rezago, pero no pudo ser ajena a males mayores: la desigualdad social, el poder de los caciques, la corrupción del gobierno local, la represión como única respuesta al descontento, la impunidad policiaca y la creciente injerencia del narcotráfico. Esas lacras no son ajenas a otras partes del país. La peculiaridad de Guerrero es que el oprobio ha sido continuamente impugnado por movimientos populares. (Villoro, 2014)

Como señala Villoro, ante la cruenta realidad social, cultural y política de la región: pobreza extrema, analfabetismo, crimen, impunidad, cacicazgo, etc., la Escuela Normal no tardó en dejar de ser indiferente a tantas problemáticas. Sus profesores y alumnos se radicalizaron como respuesta a los fenómenos que día a día asolaban a sus alumnos, padres de familia y pobladores de las comunidades donde trabajaban.

No solo se trataba de llevar la lectura, las ciencias naturales y las matemáticas a las comunidades rurales, los profesores debían lidiar con múltiples problemas, producto del rezago social de la región. En ese contexto, importantes líderes guerrilleros surgieron de las filas de normalistas de Ayotzinapa. 
Genaro Vázquez, egresado de la Escuela Normal de Ayotzinapa, se unió a la disidencia magisterial desde que era estudiante. Desde el ala revolucionaria de los profesores, mutó rápidamente hacia los movimientos de liberación nacional que más tarde se transformaron en guerrillas y movimientos armados en los sesenta y setenta en toda América Latina. En 1960, formó parte de un frente obrero y campesino que se opuso al entonces gobernador de Guerrero, el general Raúl Caballero Aburto, famoso por su perfil represor, torturador y de mano extremadamente dura:

Durante 1960, Genaro Vázquez encabezó la resistencia contra el militar, fue aprehendido el 27 de abril en las cercanías de Teloloapan y liberado el 12 de mayo siguiente; en junio realizó una caravana a la Ciudad de México y fue recibido por el presidente Adolfo López Mateos, ante quien denunció la falta de garantías constitucionales en el estado, el despojo de tierra a los campesinos, la represión por parte de pistoleros y policías, los fraudes electorales en algunos municipios y la corrupción del gobierno estatal. A su regreso a Guerrero fue detenido el 31 de octubre de 1960, acusado de injurias al gobernador y asociación delictuosa; pero el 7 de noviembre siguiente salió libre bajo fianza. Persistió en su lucha hasta lograr que el 4 de enero de 1961, se decretara la desaparición de poderes en Guerrero. (Villoro, 2014)

Tras ser perseguido, Vázquez se internó en la sierra en compañía de diversos grupos de campesinos, voluntarios y compañeros de la Normal. Sus acciones políticas y militares se extendieron prácticamente a todos los municipios de Guerrero, y tuvieron una fuerte influencia en la vida cívica del Estado. Además de acciones guerrilleras, hubo tomas de los municipios por parte de los ciudadanos simpatizantes de Vázquez, también el secuestro del entonces rector de la Universidad de Chilpancingo por parte de su grupo armado. Entonces, la represión, como respuesta, adquirió un carácter cada vez más cruento. El Ejército, con el fin de capturarlo, peinó prácticamente todas las zonas rurales del Estado, torturando y ajusticiando a sus simpatizantes e, incluso, a gente inocente. 
Genaro Vázquez fue famoso por fugarse de la prisión de Chilpancingo a inicios de los setenta, en una exitosa táctica a través de la enfermería, y fue obligado a entregarse de nuevo con la detención de su esposa, quien estaba amenazada de muerte.

Después murió en sospechosas circunstancias, supuestamente en un accidente automovilístico. Quienes iban con él juran que en realidad fue rematado a golpes por parte de la Policía y el Ejército.

Pero no llegará muy lejos, porque morirá pocos meses después de esa acción que le resultó exitosa. A fines de enero de 1972, la Dirección Federal de Seguridad, al mando de Fernando Gutiérrez Barrios, detendrá a la esposa de Genaro Vázquez, con la pretensión de obligarlo a entregarse a las autoridades. El 2 de febrero siguiente, el rebelde perecerá en un accidente automovilístico a 20 kilómetros de Morelia, Michoacán, cuando viajaba en compañía de José Bracho Campos y Salvador Flores Bello, así como de dos maestras de la sierra de Atoyac de Álvarez, Guerrero. El ejército, no la Policía de caminos, se encargará inmediatamente del accidente. No se permitirán fotos del suceso. (Villoro, 2014)

Con el mismo perfil, e igualmente egresado de la Escuela Normal de Ayotzinapa, está Lucio Cabañas, normalista de origen campesino. Desde estudiante fue secretario de la Federación de Estudiantes Campesinos Socialistas de México, en 1962. Obtuvo su plaza como profesor en el municipio de Atoyac, Guerrero, donde no tardó en ponerse a la cabeza de un movimiento que buscaba oponerse a la tala indiscriminada y explotación de los bosques a favor de empresas extranjeras y sin ningún beneficio para los campesinos de las comunidades. Como represalia, fue transferido de un municipio a otro con la esperanza de detener su lucha y se desanimara; en un momento dado se unió a Genaro Vázquez y fue parte de un fuerte movimiento de corte socialista que logró la renuncia del gobernador Aburto, en los sesenta. A manera de castigo y por petición de las empresas madereras al Gobierno, fue enviado a un lugar en la sierra de Durango para trabajar como profesor (Guerrilla Comunicacional, México, 2012).

El movimiento de Lucio Cabañas, a diferencia del de Genaro Vázquez, se caracterizó por una violencia guerrillera mayor y de más 
contundencia; tuvo una duración de 7 años en la clandestinidad, con varios golpes militares exitosos e importantes derrotas al Ejército y la Policía. Logró con éxito cuatro secuestros a empresarios, ganaderos y políticos, de lo cual obtuvo recursos financieros para proseguir su lucha. El último golpe fue el secuestro a un candidato del Partido Revolucionario Institucional (PRI), lo que le costaría muy caro a su movimiento armado.

Se dice que una vez derrotado en su última batalla, colocó su rifle en el cuello y se disparó a la garganta para evitar ser aprehendido. La milicia se precipitó entonces a darle el tiro de gracia.

\section{La Escuela Normal Rural Isidro Burgos}

La Escuela Normal Rural Isidro Burgos, mejor conocida como la Normal de Ayotzinapa, fue fundada en 1926, en el marco de un importante movimiento de reforma educativa que inauguró otras normales rurales en ese entonces, muchas de las cuales ya no existen en la actualidad, debido a la falta de apoyo gubernamental, la ausencia de recursos económicos y una fuerte hostilidad del Gobierno contra este tipo de escuelas.

Bastante de ese impulso reformador inicial aún queda en la de Ayotzinapa, por lo menos en su discurso: sus profesores y alumnado aún se concentran bajo la consigna de que la educación es un derecho popular.

Desde sus inicios, no contó con mucho apoyo por parte del Gobierno, sobre todo por sus vínculos con movimientos populares y por el accionar revolucionario de algunos de sus egresados. Algo que no es muy conocido es que cada año la Normal debe marchar para conseguir sus recursos económicos, exigiéndolos al Gobierno y solicitando apoyo económico para lograr abrir la convocatoria anual en el mes de septiembre para estudiantes de primer ingreso. Es claro que hay fuertes intereses enfocados en que a mediano plazo la escuela desaparezca. La hostilidad hacia las normales rurales cada vez es más grande:

Lo cierto es que esta escuela, como la mayoría de las otras normales rurales que integran la Federación de Estudiantes Campesinos Socialistas de México, debe de movilizarse para seguir subsistiendo. Cada año se debe arrancar al gobierno el 
presupuesto, la beca alimenticia y la convocatoria de nuevo ingreso. La lucha porque cada Normal siga existiendo es intensa.

En nuestro país, después de la matanza de estudiantes en 1968, se lanzó una campaña contra todo el normalismo rural. De entonces a la fecha, han cerrado la mayoría de este tipo de escuelas. $\mathrm{Al}$ parecer, a los gobiernos les preocupa demasiado que los estudiantes tengan mucha presencia en los pueblos y que estén siempre dispuestos a ayudarlos. Como pocas instituciones, las normales rurales interactúan con las comunidades en las que se establecen. Los alumnos que se forman como futuros maestros se preparan integralmente, tanto en lo académico, como en lo político, deportivo, cultural y productivo. El objetivo, desempeñarse como el maestro que cada comunidad necesita para paliar la pobreza y salir del atraso. (Federación de Estudiantes Campesinos Socialistas de México, 2012)

La Escuela Normal de Ayotzinapa es conocida en la región por pretender transmitir a sus alumnos una formación lo más completa posible, intentando abarcar distintos aspectos: académico, educación física, administración, historia, política y pedagogía. También, por albergar y formar estudiantes indígenas y mestizos de origen campesino, muchos de ellos procedentes de las mismas zonas marginadas del sur de México, a las cuales regresan para trabajar como educadores. De igual manera, brinda el servicio de internado a los estudiantes que provienen de regiones lejanas y no tienen dónde vivir mientras realizan sus estudios.

Del mismo modo, investigadores y expertos en educación y psicología del desarrollo han cuestionado, sobre todo en los últimos años, si en realidad la Normal no había abandonado hace mucho tiempo sus objetivos académicos y cognoscitivos, intercambiándolos por intereses políticos y demagógicos poco claros; se le ha señalado duramente el bajo perfil académico de los alumnos, académicos y egresados, y el poco destacado papel de su administración y plantel de profesores para gestionar y competir por presupuestos con otras instituciones, los cuales, al ser públicos, pueden estar al alcance de cualquiera que demuestre merecerlos; el buscar que les sean otorgadas plazas como profesores a sus egresados, de manera gratuita e inmediata, sin tener 
que prepararse y competir por ellas con otros normalistas de otras partes del país, quienes cada año no tienen más remedio que aplicar al examen de oposición nacional, con la esperanza de obtener empleo; la utilización de prácticas pedagógicas obsoletas e incluso peligrosas para el alumno, sobre todo aquellas de tintes maoístas (del líder chino Mao Tse Tung), radicalizadas hasta el fanatismo, las cuales invitan, alientan y justifican teóricamente la violencia y la destrucción en contra de los congéneres, siempre y cuando los enemigos no sean sus mismos líderes, ideólogos, orquestadores y beneficiarios financieros, desde luego; o cuestionables prácticas pedagógicas procedentes de anquilosadas tradiciones de extrema izquierda, cuya utilidad en educación está amplia e históricamente demostrada como equívoca, e incluso como contraproducente para el desarrollo humano.

Se habla del peligro de que sus principios socialistas y democráticos solo sean parte de un discurso obsoleto y petrificado, que únicamente sirve para proteger oscuros y siniestros intereses de viejos grupos de la antigua izquierda mexicana. Y que nada de lo que actualmente pregonan, o demasiado poco de lo que dicen sus alumnos y profesores, sea consecuente con lo que en verdad hacen (González de Alba, 2014). Empero, de ello se discutirá más adelante.

\section{Breve crónica de la matanza de Ayala en septiembre de 2014}

La mañana del 26 de septiembre de 2014 partieron los estudiantes desde la Normal de Ayotzinapa. Unas versiones cuentan que marcharían para celebrar el aniversario de la "Noche de Tlaltelolco", del 2 de octubre de 1968. Otras que eran parte de un grupo de primer ingreso que había sido enviado a Iguala contra su voluntad, por parte de sus profesores y dirigentes. Una novatada, según algunos autores. La finalidad, más allá de la celebración del aniversario luctuoso, era manifestarse contra el destape político de la alcaldesa como próximo gobernante (González de Alba, 2014).

Las versiones oficiales refieren que fueron atacados por la Policía municipal en dos ocasiones: 1 . Cuando los normalistas iban entrando al Zócalo de Iguala, Guerrero, fueron recibidos a fuego abierto por 
parte de la Policía de dos municipios. 2. Cuando estaban en pleno Zócalo e intentaban llevar a cabo la manifestación.

Empero, los propios estudiantes de la Normal señalan que hubo tres ataques hacia ellos. El estudiante identificado como N, anónimo, tanto su nombre como el de su comunidad de origen, internado en la Normal de Ayotzinapa, quien por cierto no participó en la manifestación, señala que los estudiantes fueron atacados en tres ocasiones, y en la última no se volvería a saber más de ellos:

Fueron tres ataques, aclara N., y no dos, como manejan las autoridades. El primero, alrededor de las 20:00 horas, cuando los normalistas se encontraban en el Zócalo de Iguala luego de haber realizado una colecta, y fue entonces cuando "se empezaron a escuchar disparos. Si fueron disparos al aire o directo contra la gente, no lo sabemos, pero sí sabemos que hubo disparos, porque muchas (de las 17) personas heridas fueron lesionadas ahí”.

Para protegerse, narra, los normalistas abordaron los tres autobuses en los que llegaron a Iguala y cuando todos lograron agruparse, emprendieron el camino de vuelta a Ayotzinapa.

Fue aproximadamente una hora después de que se escucharan los primeros disparos cuando, a la altura de la avenida Álvarez, policías municipales abrieron fuego contra los vehículos de los normalistas, así como contra un vehículo en donde viajaban los jugadores del equipo de futbol "Los Avispones”, y contra un taxi, dejando tres normalistas fallecidos, lo mismo que un futbolista y los tripulantes del taxi (el chofer y una pasajera). (Martínez, 2014)

El tercer ataque, señala $\mathrm{N}$, fue entre las 22:00 y 23:00 horas, cuando los normalistas sobrevivientes, aún en Iguala, intentaron dar una conferencia de prensa para denunciar la agresión sufrida. En este momento, un grupo de hombres armados disparó nuevamente en su contra, poniéndolos en fuga, y en este momento 44 de ellos desaparecieron (según la cifra reconocida por la Comisión Nacional de Derechos Humanos y que se basa en los testimonios de las familias de los normalistas raptados, 2014). La prensa indica que murieron 
seis en el primer encuentro. Se sabe también que intentaron, posteriormente, regresar a Ayotzinapa, y a la salida de la ciudad fueron atacados de nuevo. Fue la última vez que se supo de ellos.

Múltiples versiones posteriores revelaron que la orden del ataque y la violenta represión fue dictada por el propio alcalde, José Luis Abarca, y por su esposa, la alcaldesa María de los Ángeles Pineda, de quien se tiene noticia que tomaba buena parte de las decisiones políticas y administrativas del municipio durante el mandato de su marido. De ella se sabe que también poseía vínculos históricos con el crimen organizado, particularmente con el famoso Cartel del Golfo, de los hermanos Beltrán Leyva.

Tras ser detenidos por los policías, los normalistas fueron entregados a un grupo ultraviolento del crimen organizado, los Guerreros Unidos, quienes constituían el brazo armado del alcalde Abarca y su esposa. Los criminales se encargaron de torturarlos, ejecutarlos $\mathrm{y}$, presuntamente, incinerar sus restos durante horas en un basurero, y posteriormente arrojaron sus cenizas al lecho contaminado de un río (CNN Noticias en Español, 2014).

\section{La pareja real: el alcalde Abarca y su señora}

Abarca y su mujer eran conocidos en la región como la pareja real, tanto por su autoritarismo y su actuar, porque se consideraban a sí mismos intocables, como por sus fuertes vínculos con poderosos grupos del crimen organizado, gracias a los cuales conseguían hacer siempre su voluntad; en muchas ocasiones, por medio de la fuerza bruta: secuestrando, ejecutando y haciendo desaparecer a quien fuera que se opusiera a sus intereses.

Abarca provenía de una familia muy humilde de artesanos, fabricantes y vendedores de sombreros. Hace 35 años abandonó el ramo de la sombrerería para dedicarse al comercio de oro y joyas. Se sabe que una tía lo introdujo en el nuevo negocio.

Al parecer, gracias a la prosperidad de la venta de oro, Abarca logró amasar una considerable fortuna. Hasta antes de su detención, poseía tres grandes joyerías bien establecidas en tres importantes plazas comerciales de Iguala. Llegó a amasar una fortuna millonaria e, 
incluso, logró realizar una inversión de 300 millones de pesos en su ciudad, construyendo la Plaza Tamarindos, la cual fue saqueada por manifestantes tras la desaparición de los normalistas.

En algún punto, gracias a su fortuna y a los vínculos de su mujer con el Cartel de los Beltrán Leyva, logró colarse en las filas de la política local, particularmente del ala de los partidos de izquierda, con el PRD, Movimiento Ciudadano y Morena. Con pleno y absoluto apoyo de importantes figuras de la política nacional y local (Becerril, 2014).

Cuentan que en una tienda de vestidos de boda de su padre, Abarca vio por primera vez a María de los Ángeles, la que sería su mujer. A ella se le tiene identificada como operadora del Cartel de los Guerreros Unidos, que surgió tras la aprensión y muerte de los líderes del Cartel del Golfo.

Abarca debía la vida no solo de los estudiantes, sino de importantes líderes opositores de grupos disidentes, a quienes ejecutó él mismo, según se dice, a punta de pistola (Becerril, 2014). Por su parte, la señora alcaldesa tenía vínculos familiares históricos con el Cartel del Golfo. Cuando sus miembros fueron apresados y detenidos o ejecutados, en los últimos dos años, dicho grupo delictivo se fraccionó, y dejó a diversos grupúsculos actuando de manera relativamente independiente. Algunos de ellos se pasaron del lado de sus enemigos, el Cartel del Golfo, para continuar trabajando como sicarios y pistoleros, otros conformaron un nuevo grupo: los Zetas, y otros más se reorganizaron en los famosos Guerreros Unidos, precisamente en Guerrero.

Sus padres y hermanos también trabajaron, en su momento, desde décadas atrás, para los Beltrán Leyva. De hecho, dos de sus hermanos murieron ejecutados en los últimos años. La pareja conformada por sus padres fueron durante los años noventa responsables del narcomenudeo en esa región (Vicenteño, 2014).

María de los Ángeles y su marido, el alcalde, celebraban un baile mientras el autobús de los desaparecidos normalistas ingresaba a la ciudad. Diversas versiones revelan que tanto a la pareja real como a los policías de la región les surgió la idea de que los normalistas de Ayotzinapa iban para boicotear el evento de los gobernantes. Aparentemente, la orden de ataque hacia el transporte de los estudiantes fue emitida en el mismo momento de la celebración; se dice 
que fue ella misma, María de los Ángeles, apoyada por su marido, quien dio las instrucciones de la agresión. Primero a la Policía y luego hacia el brazo armado conformado por los Guerreros Unidos.

Desde varios años atrás, se conocía el vínculo de la pareja con el crimen organizado, tanto por parte del gobierno del Estado como por el federal. Abarca y su mujer contaron con el apoyo político de la alianza de partidos de izquierda cuando llegaron al poder, durante su mandato y cuando manifestaron su franca intención de que la señora Ángeles fuera la futura candidata. Nada hubiera detenido a la señora en sus aspiraciones políticas de no ser por el cruento suceso de los normalistas.

Tras conocerse la desaparición de los estudiantes y que en breve el hecho se volviera un evento de tinte internacional, Abarca y la señora huyeron del Estado, e intentaron ampararse previamente. Fueron detenidos dos meses más tarde en la Ciudad de México, ocultos en una miserable residencia abandonada, en compañía de sus ocho perros, protegidos y alimentados por una amiga de su hija.

\section{Ultraviolencia de narcoestado: un caso monstruoso de tortura}

Julio César Mondragón era estudiante de primer semestre de la Normal, en Ayotzinapa. Originario del Estado de México, embarazó a su joven esposa pocos meses antes de salir en listas de admisión en la Normal. Desde la preparatoria, tuvo fuertes inclinaciones sociales; de hecho, Psicología Social en la Universidad Autónoma Metropolitana Xochimilco fue su primera opción. Sin embargo, también deseaba vivir la experiencia de estudiar fuera de la casa de sus padres, en el Estado de México y del Distrito Federal, lugares en donde había pasado toda su vida. La tradición de la Normal, en Guerrero, siempre lo atrajo, sobre todo por la fama de algunos de sus egresados, principalmente Lucio Cabañas, a quien admiraba y de quien conocía bastante sobre su vida. Como no salió en listas de ingreso los dos primeros semestres en la Facultad de Psicología Social, dada la fuerte demanda de esta escuela, apuntó todas sus energías en Ayotzinapa. 
De la Normal conocía que principalmente recibía a estudiantes de origen campesino e indígena, procedentes de zonas marginadas de la sierra de Guerrero, el Estado de México, e inclusive Chiapas y Oaxaca. Como era oriundo de una zona urbana bastante grande en Toluca, dudaba de que existiera la posibilidad de ganarse una plaza ahí.

Cuando su nombre apareció en las listas, lleno de ilusión, prometió a su esposa, ya en cinta, que no tardaría en llevársela con él a vivir a su nuevo hogar. Planificaban todo un futuro: vivir en Guerrero hasta que en julio se graduara, conseguir una plaza como profesor e irse a vivir juntos a donde los mandaran. Una pequeña niña nació los primeros meses de sus estudios en Guerrero. En el mes de septiembre, Melisa, la esposa, dejó de saber de él, hasta que comenzó a circular en las redes sociales una horrible imagen con su fotografía.

Una semana después del ataque a los estudiantes de Iguala la contactaron para que viajara hasta Guerrero a reconocer el cadáver de su pareja. La muchacha no imaginaba lo que estaba a punto de presenciar; descubrió que a Julio César lo habían desollado vivo y su rostro le había sido arrancado en medio de sus gritos, en plena calle de Iguala:

La imagen impactante que circulaba en redes sociales pronto llegó a los ojos de Marisa, esposa de Julio y madre de su hija, Melisa Sayuri, de apenas tres meses de edad. Marisa y el tío Guillermo Fontes viajaron a Iguala a reconocer y recoger el cuerpo destrozado, herido, mancillado, del joven estudiante de 22 años que murió en su deseo de ser maestro. El médico forense y otros burócratas explicaron: "fue desollado vivo". La aseveración se corrobora, entre otras cosas, por la forma en que sus restos mantienen los dientes y mandíbula apretados. El dolor debió ser inimaginable.

Fue pronto y discreto el regreso de Iguala. Ya en casa, la familia organizó el entierro y novenario para Julio; el levantamiento de la cruz se realizó el 9 de octubre. Los amigos y familiares que le conocen bien aseguran que Julio era valiente, entregado, decidido, no dudan que cuerpo a cuerpo hubiese salido avante en una lucha, “ipero así, armados y en bola, lo despedazaron!”. (Herrera Román, 2014) 
Versiones recientes revelan que se trataba de una "novatada" común entre el estudiantado de la Normal, sobre todo con los de primer ingreso. La mayoría de los estudiantes del autobús ultrajado eran de primero, de hecho. Hay quien considera, con evidencias, que quienes enviaron a los estudiantes desde la Normal poseían cierto conocimiento del peligro al que se enfrentarían los chicos y lo que eventualmente podría sucederles al confrontarse con el alcalde y sus aliados (Luis González de Alba, 2014).

El punto es que el caso resulta un hecho de violencia sin límites sobre víctimas, de un lado, y de otro, un evento donde la violencia se vuelve cada vez más cotidiana. El cadáver de Julio César quedó desollado en medio de la plaza de Iguala, los forenses indicaron, por la expresión tan tensa de sus dientes al morir, que su rostro le fue arrancado mientras aún estaba vivo. 


\section{Bibliografía}

Becerril, A. (4 de noviembre de 2014). Perfil de José Luis Abarca: Llenó Iguala de joyas e impunidad. Excélsior.

CNN Noticias en Español. (5 de noviembre de 2014). José Luis Abarca, recluido en un penal federal; su esposa, bajo arraigo. Recuperado de http://mexico.cnn.com/nacional/2014/11/05/ jose-luis-abarca-recluido-en-un-penal-federal-su-esposa-bajo-arraigo

El Financiero. (9 de febrero de 2016). Restos de 19 personas no son de los 43 normalistas: EAAF. Recuperado de http://eleconomista.com.mx/ sociedad/2016/02/09/no-hay-evidencia-quema-estudiantes-cocula-eaaf

Federación de Estudiantes Campesinos Socialistas de México. (Febrero de 2012). Ayotzinapa, de Pie. Revista Contralínea. Recuperado de http:// contralinea.info/archivo-revista/index.php/2012/02/05/ayotzinapa-de-pie/

Guerrilla Comunicacional, México. (2012). ¿Quién fue Lucio Cabañas Barrientos. Recuperado de http://gcmx.wordpress.com/2013/12/02/ quien-fue-lucio-cabanas-barrientos/

Herrera Román, S. (5 de noviembre de 2014). ¿Por qué torturaron hasta la muerte al normalista Julio César Mondragón? Animal Político. Recuperado de http:/www.animalpolitico.com/blogueros-la-dignidad-en-nuestras-manos/2014/11/05/memoria-verdad-y-justicia-para-el-normalista-julio-cesar-mondragon-fontes/

Letra Roja. (7 de febrero de 2016). 3 de cada 4 desapariciones en Guerrero ocurrieron en Iguala. Recuperado de http://www.letraroja.com. $\mathrm{mx} / 3$-de-cada-4-desapariciones-en-guerrero-ocurrieron-en-iguala/

Martínez, P. (7 de octubre de 2014). Fueron 3 los ataques en Iguala, y no 2, como dicen las autoridades. Crónica desde Ayotzinapa. Animal Político. Recuperado de http://www.animalpolitico.com/2014/10/ por-que-vivir-como-normalista-por-que-morir-como-normalista/

Tagle, T. (10 de noviembre de 2014). Breve apología de la violencia como acto de sobrevivencia. Medium.com. Recuperado de https://medium.com/@ Tania_Tagle/breve-apologia-de-la-violencia-como-acto-de-sobrevivencia-face 4 f054700

Vicenteño, D. (4 de noviembre de 2014). PERFIL de María de los Ángeles Pineda Villa: él administraba; ella tenía el mando. Excélsior.

Villoro, J. (4 de noviembre de 2014). Yo sé leer: vida y muerte en Guerrero. Educación Futura.Org. México. Recuperado de http://www.educacionfutura.org/yo-se-leer-vida-y-muerte-en-guerrero/ 